\title{
Liver transplant oncology: is it time to revisit our ideas?
}

\author{
Ramon Soliva, Joan Figueras \\ Hepatobiliary and Pancreatic Surgery, Department of Digestive Surgery, Sagrat Cor University Hospital, Barcelona, Spain \\ Correspondence to: Joan Figueras, MD, PhD, ESA, AFC, E-AHPBA (hon). Consultant of Hepatobiliary and Pancreatic Surgery, Department of \\ Digestive Surgery, Sagrat Cor University Hospital, C/Viladomat 170, Barcelona 08022, Spain. Email: jfigueras.net@icloud.com. \\ Comment on: Dueland S, Yaqub S, Syversveen T, et al. Survival Outcomes After Portal Vein Embolization and Liver Resection Compared With Liver \\ Transplant for Patients With Extensive Colorectal Cancer Liver Metastases. JAMA Surg 2021;156:550-7.
}

Submitted Aug 31, 2021. Accepted for publication Sep 13, 2021.

doi: 10.21037/hbsn-2021-20

View this article at: https://dx.doi.org/10.21037/hbsn-2021-20

Scarcity of cadaveric liver donors compared with the large number of patients with liver disease has been considered the main obstacle to use liver transplantation (LT) to treat hepatic malignancies and for the development of transplant oncology.

It is known that we are experiencing a true paradigm shift in the fundamental problem of transplantology, which is none other than the imbalance between donation and graft implants (1). Because the most common indication of LT in most countries [hepatitis $\mathrm{C}$ virus ( $\mathrm{HCV}$ ) cirrhosis] has started to decrease in the waiting lists $(2,3)$. One might think that, for the first time in many years in Western countries, we could find a higher supply of organs than recipients for them.

In the last decade, great advances in the understanding of the genome and protein structure of the HCV have allowed the improvement of efficacy of its infection treatment. Multiple direct-acting antivirals (DAA) that target specific steps of the virus life cycle have been developed (4). Defined by their mechanism of action, four classes of DAA are described:

(I) Non-structural proteins 3/4 (NS3/4A) protease inhibitors (PIs) (suffix "previr");

(II) NS5B nucleoside polymerase inhibitors (NPIs) (suffix "buvir");

(III) NS5B non-nucleoside polymerase inhibitors (NNPIs);

(IV) NS5A inhibitor (suffix "asvir").

Most DAA are used as part of mixed-dose combinations for the treatment of chronic HCV disease. The treatment results in more than $90 \%$ sustained response of the hepatitis without undetectable HCV copies in the PCR blood examination. The use of second generation DAA agents since 2013 in the treatment of HCV infection has decreased the rate of LT waiting list for HCV complicated by decompensated cirrhosis by over $30 \%(3,4)$. Progressively diminished this end-stage liver disease as a leading indication for LT in most Western countries, such as the USA and Spain $(5,6)$.

Scandinavia is a region where this has already happened. Primary sclerosing cholangitis, acute hepatic failure, alcoholic liver disease, primary biliary cirrhosis and hepatocellular carcinoma (HCC) have been historically the five most frequent primary indications, in this order, for LT in Scandinavian countries. Although over the recent years, there has been a steadily increasing number of patients referred for LT due to HCV cirrhosis, up to more than $10 \%$ of all indications of LT. HCV infection epidemic seems to have a time-shift as compared with the rest of the Western world. HCV and hepatitis B virus (HBV) prevalence has been low in the Nordic countries and cirrhosis due chronic $\mathrm{C}$ or B viral infection has accounted for only a small proportion of LT there (7). So, the lack of HCV cirrhotic patients to be transplanted, improved expanded oncologic criteria for LT, because the liver graft offer starts to exceed the demand.

Primary and secondary hepatic tumors have been considered formally a contraindication for LT. There are some accepted exceptions in very selected cases of small localized HCC following the Milan criteria (8), because survival after LT in patients with liver cirrhosis is similar to patients with small HCC (9). Other accepted indications for LT are hepatic metastases of well differentiated neuroendocrine tumors. 
Hepatic metastases of colorectal carcinoma (CRC) are the most frequent secondary tumor of the liver. LT for hepatic metastases of CRC was performed at the beginning of LT with a 5 -year overall survival (OS) of less than $20 \%$. Due to the dismal results and the scarcity of cadaveric liver donor, LT was abandoned at that time.

However, during the last 30 years response to chemotherapy for CRC has dramatically improved. Results of LT are also better with a postoperative mortality lower than $10 \%$. For these reasons LT has recently been proposed as an alternative treatment for unresectable colorectal liver metastases in selected patients with a $60 \%$ estimated $\mathrm{OS}$ at 5 years in a recent (SECAI) prospective Norwegian study (10). However, disease-free survival (DFS) in this preliminary study was poor with a $90 \%$ recurrence after LT.

A standard immunosuppressive protocol proposed by the University of Oslo team for unresectable CRC liver metastases consists of avoiding as early as possible calcineurin inhibitors and including antiproliferative immunosuppressors. Induction immunosuppression consists of Basiliximab (an anti-CD25 monoclonal antibody), tacrolimus (an anticalcineurin inhibitor) for 4-6 weeks and then conversion to sirolimus (an M-TOR inhibitor). Glucocorticoids and mofetil mycophenolate (MMF) are also used during the induction immunosuppression for 3-6 months.

In a more recent study from the same group (SECAII), 15 patients were treated by LT for liver-only metastases of CRC (11). The patients had more than one year from diagnosis of CRC liver metastases and time of listing for LT. Extrahepatic disease was discarded using positron emission tomography and computed tomography (PET-CT) and at least $10 \%$ response to chemotherapy was required. Tumors were smaller than $5 \mathrm{~cm}$ after chemotherapy and carcinoembryonic antigen (CEA) lower than $30 \mu \mathrm{g} / \mathrm{mL}$. OS at 1,3 and 5 years were $100 \%, 83 \%$ and $83 \%$. The $1-, 3-$ and 5 -year DFS were $100 \%, 73 \%$ and $73 \%$. In the SECAI study all patients that have been observed for more than 11 months after LT presented a recurrence. While in the SECAII study 4 patients had no relapse with a follow-up of 31 to 49 months.

These results should be considered excellent and suggest that liver metastases of CRC may be considered a good indication for LT in very selected patients with liver-only CRC metastases.

However, several authors showed their disagreement with various aspects of the study (12). Criteria for unresectability varies greatly among surgeons in different centers and studies. Techniques of liver resection for CRC liver metastases has also improved with the introduction of portal vein embolization (PVE), two stage liver resection, associating liver partition and portal vein ligation for staged hepatectomy (ALPPS) procedure and other surgical techniques have greatly extended our ability to safety resect many lesions from the liver and should be considered an alternative to LT (12).

A novel concept published in 2015 was a hybrid of the auxiliary LT and the ALPPS procedure (13). The resection and partial liver segments 2-3 LT with delayed total hepatectomy (RAPID) propose a two stage hepatectomy. The first step consists of segment $1-3$ resection and transplantation of a left lateral segment (2 and 3) graft. After the donor graft reaches the $0.8 \%$ body weight, or $35-45 \%$ standard liver volume, a standardized portion of the native liver is resected.

In the March issue of JAMA Surgery, the Oslo group presents original investigation data that see LT for CRC in a new light (14). Fifty patients with unresectable liver metastases of CRC, previously enrolled in LT studies between 2006-2019, were compared with a retrospective cohort of well-matched 53 patients with similar selection criteria who underwent PVE and liver resection. In an intention to treat analysis, fifteen (28\%) of the PVE group did not undergo liver resection due to tumor progression or insufficient liver regeneration. All patients enrolled in the transplant list underwent LT.

For each patient the tumor burden score (TBS) was calculated. TBS is the Cartesian result using the Pythagorean theorem of the maximal tumor diameter and number of LM. Patients were divided in 3 groups, according to the TBS model. Zone 1 (TBS $<3$ ), zone 2 (TBS 3 to <9) and zone 3 (TBS >9) (15). There were no differences among 3 groups regarding the TBS.

In the PVE group, there was a significant difference in 5-year OS between patients who underwent only PVE $0 \%$ and PVE with liver resection $40 \%$. There was also a significant difference in 5 years of OS in patients of the PVE with low $50 \%$ and high TBS $8 \%$.

Among the patients in the LT group there was a significant difference in 5-year OS, when the primary tumor had a high TBS. In the ascending sided primary tumor 5-year OS was 20\% while in the sigmoid and left sided primary tumor was $60 \%$ in the high TBS groups. This study demonstrates that LT has a definitive role in the treatment of liver-only CRC metastases and is superior to other surgical techniques like PVE.

However, considering the scarcity of cadaveric donors, 
it is important to select the best candidates with the highest possibilities of survival. In patients with high TBS, a rightsided primary has a low survival. LT should be indicated with caution in this group of patients.

There is, however, an ongoing multicenter liver transplant trial (Transmet). Patients with liver-only metastases of CRC are randomized comparing patients receiving neoadjuvant chemotherapy and LT, versus chemotherapy alone. The endpoint is the 5-year OS. Results will show the real role of chemotherapy with or without LT (16).

We dare to conclude that what for a long time was considered a practically absolute contraindication for LT nowadays is beginning to be thought of as a growing indication with a solid future. So, without any doubts, the era of transplant oncology has already started (17).

\section{Acknowledgments}

Funding: None.

\section{Footnote}

Provenance and Peer Review: This article was commissioned by the editorial office, Hepatobiliary Surgery and Nutrition. The article did not undergo external peer review.

Conflicts of Interest: Both authors have completed the ICMJE uniform disclosure form (available at https://hbsn. amegroups.com/article/view/10.21037/hbsn-2021-20/coif). The authors have no conflicts of interest to declare.

Ethical Statement: The authors are accountable for all aspects of the work in ensuring that questions related to the accuracy or integrity of any part of the work are appropriately investigated and resolved.

Open Access Statement: This is an Open Access article distributed in accordance with the Creative Commons Attribution-NonCommercial-NoDerivs 4.0 International License (CC BY-NC-ND 4.0), which permits the noncommercial replication and distribution of the article with the strict proviso that no changes or edits are made and the original work is properly cited (including links to both the formal publication through the relevant DOI and the license). See: https://creativecommons.org/licenses/by-ncnd $/ 4.0 \%$.

\section{References}

1. Boratyńska M, Patrzałek D. Transplantology: Challenges for Today. Arch Immunol Ther Exp (Warsz) 2016;64:37-45.

2. Goldberg D, Ditah IC, Saeian K, et al. Changes in the Prevalence of Hepatitis C Virus Infection, Nonalcoholic Steatohepatitis, and Alcoholic Liver Disease Among Patients With Cirrhosis or Liver Failure on the Waitlist for Liver Transplantation. Gastroenterology 2017;152:1090-1099.e1.

3. Poordad F, Dieterich D. Treating hepatitis C: current standard of care and emerging direct-acting antiviral agents. J Viral Hepat 2012;19:449-64.

4. Cholankeril G, Ahmed A. Alcoholic Liver Disease Replaces Hepatitis C Virus Infection as the Leading Indication for Liver Transplantation in the United States. Clin Gastroenterol Hepatol 2018;16:1356-8.

5. Flemming JA, Kim WR, Brosgart CL, et al. Reduction in liver transplant wait-listing in the era of direct-acting antiviral therapy. Hepatology 2017;65:804-12.

6. Pardo F, Pons JA, Castells L, et al. VI consensus document by the Spanish Liver Transplantation Society. Gastroenterol Hepatol 2018;41:406-21.

7. Fosby B, Melum E, Bjøro K, et al. Liver transplantation in the Nordic countries - An intention to treat and post-transplant analysis from The Nordic Liver Transplant Registry 1982-2013. Scand J Gastroenterol 2015;50:797-808.

8. Mazzaferro V, Regalia E, Doci R, et al. Liver transplantation for the treatment of small hepatocellular carcinomas in patients with cirrhosis. $\mathrm{N}$ Engl J Med 1996;334:693-9.

9. Figueras J, Jaurrieta E, Valls C, et al. Survival after liver transplantation in cirrhotic patients with and without hepatocellular carcinoma: a comparative study. Hepatology 1997;25:1485-9.

10. Hagness M, Foss A, Line PD, et al. Liver transplantation for nonresectable liver metastases from colorectal cancer. Ann Surg 2013;257:800-6.

11. Dueland S, Syversveen T, Solheim JM, et al. Survival Following Liver Transplantation for Patients With Nonresectable Liver-only Colorectal Metastases. Ann Surg 2020;271:212-8.

12. Azoulay D, Lim C. Comment on "Survival Following Liver Transplantation for Patients With Nonresectable Liver-only Colorectal Metastases": Shaking the Coconut 
Tree. Ann Surg 2020;271:e122-4.

13. Line PD, Hagness M, Berstad AE, et al. A Novel Concept for Partial Liver Transplantation in Nonresectable Colorectal Liver Metastases: The RAPID Concept. Ann Surg 2015;262:e5-9.

14. Dueland S, Yaqub S, Syversveen T, et al. Survival Outcomes After Portal Vein Embolization and Liver Resection Compared With Liver Transplant for Patients With Extensive Colorectal Cancer Liver Metastases. JAMA Surg 2021;156:550-7.

15. Sasaki K, Morioka D, Conci S, et al. The Tumor Burden

Cite this article as: Soliva R, Figueras J. Liver transplant oncology: is it time to revisit our ideas? HepatoBiliary Surg Nutr 2021;10(6):864-867. doi: 10.21037/hbsn-2021-20
Score: A New "Metro-ticket" Prognostic Tool For Colorectal Liver Metastases Based on Tumor Size and Number of Tumors. Ann Surg 2018;267:132-41.

16. Available online: https://clinicaltrials.gov/ct2/show/ NCT02597348

17. Bonney GK, Chew CA, Lodge P, et al. Liver transplantation for non-resectable colorectal liver metastases: the International Hepato-Pancreato-Biliary Association consensus guidelines. Lancet Gastroenterol Hepatol 2021;S2468-1253(21)00219-3. [Epub ahead of print]. doi:10.1016/S2468-1253(21)00219-3. 